\title{
A New Technique Using Axially Slotted Microstrip Line for Antenna Impedance Matching Designs
}

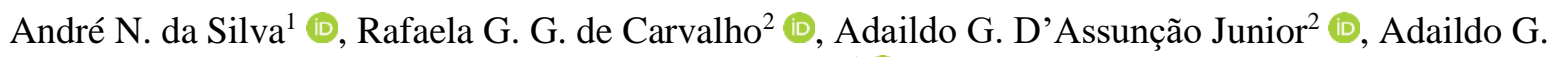 \\ D’Assunção ${ }^{1}$ (D) \\ ${ }^{1}$ Federal University of Rio Grande do Norte, UFRN, Natal, RN, Brazil, eng.andrensilva@gmail.com and \\ adaildo@ymail.com \\ ${ }^{2}$ Federal Institute of Education, Science and Technology of Paraíba, IFPB, João Pessoa, PB, Brazil, \\ rafaelaggc@gmail.com and adaildo.assuncao@ifpb.edu.br
}

\begin{abstract}
A new technique is presented for designing microstrip patch antennas with very good input impedance matching. The analysis is carried out for $1.78 \mathrm{GHz}, 2.42 \mathrm{GHz}$ and $3.46 \mathrm{GHz}$ rectangular patch antennas printed on low-cost fiberglass substrates (FR-4), mounted on a ground plane and fed by a microstrip line. The antenna impedance matching is obtained using a slotted microstrip line feeder. The use of the proposed impedance matching technique showed considerable improvement from the reflection coefficient point of view, with reduction of about $20 \mathrm{~dB}$ at the resonant frequency, without modifying the original dimensions of the antenna patch elements or the width of the feeding microstrip line. Numerical characterization is carried out using Ansoft Designer software and iterative method WCIP. Prototypes are fabricated and measured, for validation purpose, showing good agreement when compared to simulated results.
\end{abstract}

Index Terms - Slotted microstrip, slotted feeder, impedance matching, microstrip antenna, WCIP.

\section{INTRODUCTION}

Microstrip antennas are being widely used in wireless communication system applications because of small size, low weight, ease of integration with other parts of the circuits, low manufacturing cost, and ability to take part in a design without significant hardware changes, arousing a lot of interest from researchers worldwide.

As shown in Fig. 1, a microstrip antenna basically consists of a conducting patch and a parallel ground plane, separated by a dielectric substrate, usually fed by a microstrip line or a coaxial probe [1]. The conducting patch is made of copper and may have many different shapes, such as rectangular [1], circular [2], annular ring [3], fractals [4]-[5], and metamaterial inspired [6]-[8].

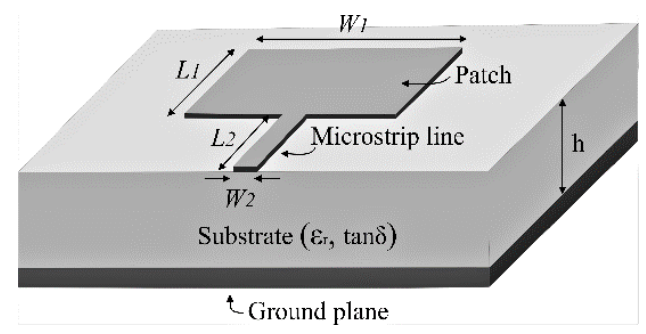

Fig. 1. Illustration of a rectangular patch microstrip antenna. 
The feeding structure is an important issue in printed antenna designs. It is a transition between the feeding microstrip line and the radiating structure providing an efficient mechanism for electromagnetic wave transmission between them. In addition, the feeding structure can affect the antenna overall performance, changing its main parameters such as resonant frequency, bandwidth, radiation pattern, and radiation efficiency [1], [9]. Several impedance matching techniques have been developed for microstrip line and coaxial cable printed antenna excitation, such as $\lambda / 4$ impedance transformers [10], [11], stubs [12], [13], inset-feed [14], [15], and probe feed [16], as shown in Fig. 2.

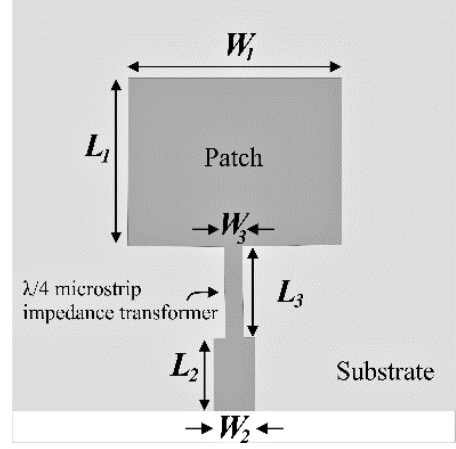

(a)

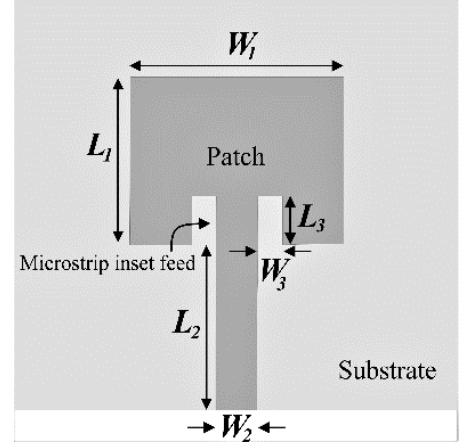

(c)

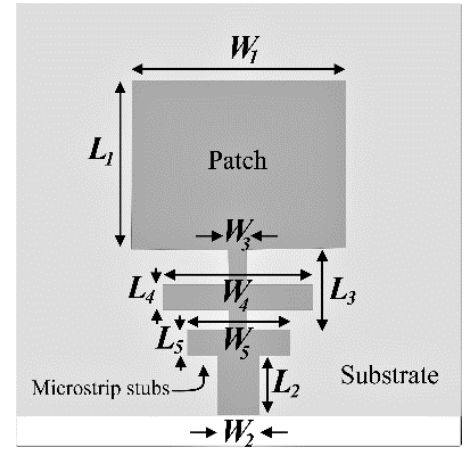

(b)

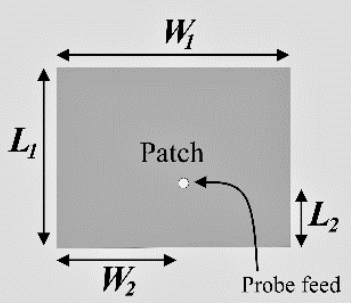

Substrate

(d)

Fig. 2. Impedance matching technique using (a) $\lambda / 4$ microstrip impedance transformer, (b) microstrip stubs, (c) microstrip inset-feed, and (d) probe feed.

This work proposes to carry out the impedance matching between a microstrip line and a patch antenna by inserting a narrow slot in the conducting strip of the microstrip line. The proposed technique is tested through parametric simulation, using Ansoft Designer and WCIP Method, of microstrip antenna structures fed by a narrow slotted microstrip line, with length $L_{3}$ and width $W_{3}$ (Fig. 3). In addition, prototypes are fabricated and measured, for validation purpose.

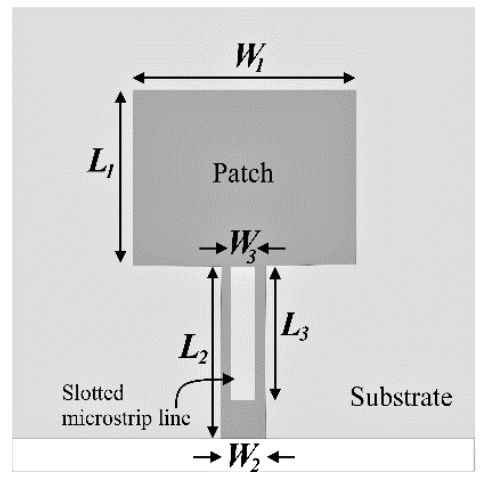

Fig. 3. Patch antenna feeding using the proposed slotted microstrip line geometry with width $W_{3}$ and length $L_{3}$. 


\section{WCIP METHOD}

The wave concept iterative procedure (WCIP) is an iterative method based on incident wave, A, and its relationship with the reflected wave, B, by a surface $S$. This process is represented by two equations, shown in (1) and (2), that describes the relationship between the incident and reflected waves, shown [17]-[22].

$$
\begin{aligned}
& A=S_{x y} B+A_{0} \\
& B=\Gamma A
\end{aligned}
$$

Where, $S_{x y}$ describes boundary conditions at the subregions of the interface $S$, and $\Gamma$ describes the propagation characteristics in the surrounding medium.

The solution of the electric field on the interface is achieved when occurs the convergence of iterative procedure.

\section{Proposed Antenna Geometry And Results}

The Microstrip Patch Antenna Calculator [23] is used to define the length $(L)$ and width $(W)$ of a rectangular microstrip patch antenna at the given resonant frequencies of $1.8 \mathrm{GHz}, 2.45 \mathrm{GHz}$ and 3.5 $\mathrm{GHz}$, covering 4G, Wireless / Bluetooth, and 5G frequency bands, respectively. The parametric analysis is done for rectangular patch microstrip antennas using Ansoft Designer software, which presented a maximum deviation of $1.22 \%$ from initially designed resonance frequencies. Therefore, the considered operating frequencies of the investigated antennas are $1.78 \mathrm{GHz}, 2.42 \mathrm{GHz}$, and 3.46 GHz. The antennas are printed on low-cost fiberglass (FR-4) substrates, with relative permittivity $\varepsilon_{r}=$ 4.4, loss tangent $\tan \delta=0.02$, and thickness $h=1.5 \mathrm{~mm}$.

The antenna impedance matching is carried out using a narrow slotted microstrip line (Fig. 3). The characteristic impedance of the original microstrip line (without narrow slot) is $50 \Omega$. The patch antennas structural parameters are summarized in Table I.

TABLE I. ANTENNAS STRUCTURAL PARAMETERS FOR $\mathrm{W}_{3}=0 \mathrm{MM}$ AND L $3=19.92 \mathrm{MM}$.

\begin{tabular}{cccccc}
\hline Resonant frequency $(\mathbf{G H z})$ & $\boldsymbol{W}_{\boldsymbol{1}}(\mathbf{m m})$ & $\boldsymbol{W}_{\mathbf{2}}(\mathbf{m m})$ & $\boldsymbol{L}_{\boldsymbol{1}}(\mathbf{m m})$ & $\boldsymbol{L}_{\mathbf{2}}(\mathbf{m m})$ & $\boldsymbol{L}_{\boldsymbol{3}}(\mathbf{m m})$ \\
\hline 1.78 & 50.71 & 2.87 & 39.46 & 22.83 & 19.96 \\
2.42 & 37.26 & 2.87 & 28.87 & 16.77 & 13.90 \\
3.46 & 26.08 & 2.87 & 20.03 & 11.74 & 8.87 \\
\hline
\end{tabular}

To minimize the reflection coefficient, $\left|s_{11}\right|$, the input impedance of the narrow slotted microstrip line should be transformed to approximately $50 \Omega$, corresponding to a reflection coefficient close to zero. The impedance matching analysis is performed varying the line width, $W_{3}$, from 0 to $2.4 \mathrm{~mm}$.

Simulation is performed using Ansoft Designer, for the antenna's geometry shown in Fig. 3, varying the width, $W_{3}$, of the inserted slot in the conducting strip of the microstrip line. Simulation results are presented in Figs. 4, 5, and 6, and summarized in Table II. For the 1.3 to 2.3 (GHz), 2 to 3 $(\mathrm{GHz})$, and 3 to $4(\mathrm{GHz})$ frequency ranges, simulation results for the input reflection coefficient of the proposed antennas are obtained, for different values of the slotted microstrip line width $W_{3}$. 


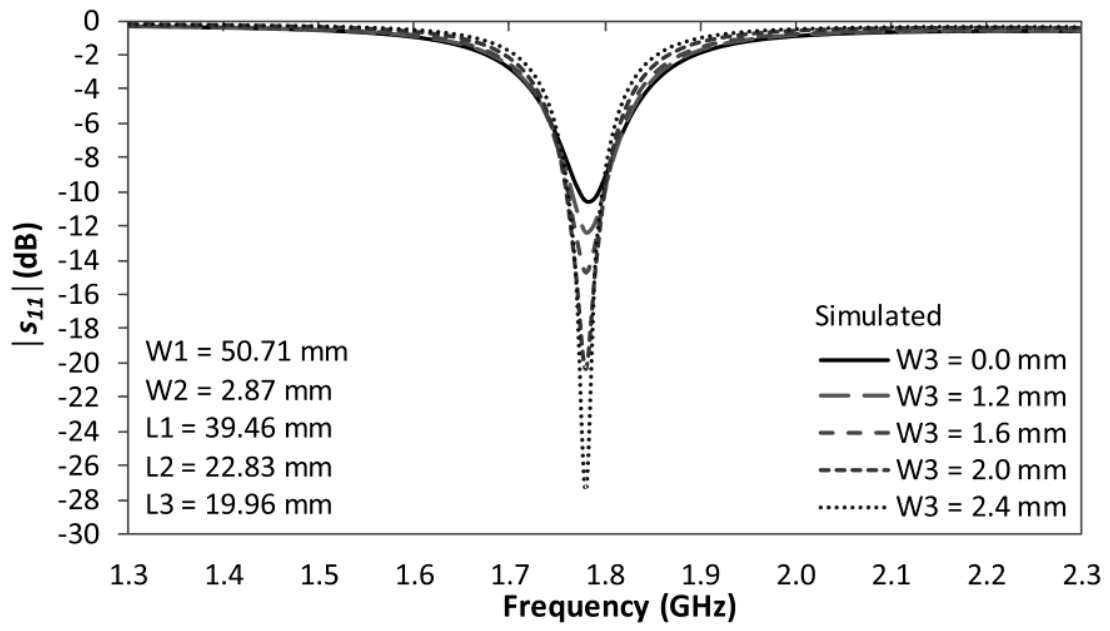

Fig. 4. Reflection coefficient simulation results for the proposed antenna for operation at $1.78 \mathrm{GHz}$ with $L_{3}=19.96 \mathrm{~mm}$ and different values of $W_{3}$.

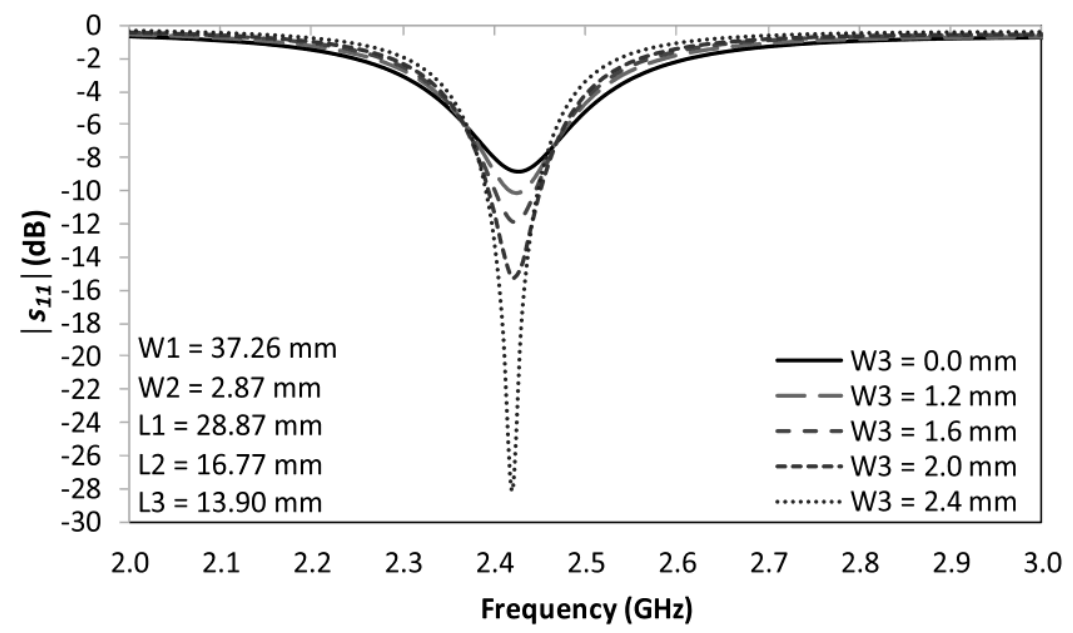

Fig. 5. Reflection coefficient simulation results for the proposed antenna for operation at $2.42 \mathrm{GHz}$ with $L_{3}=13.90 \mathrm{~mm}$ and different values of $W_{3}$.

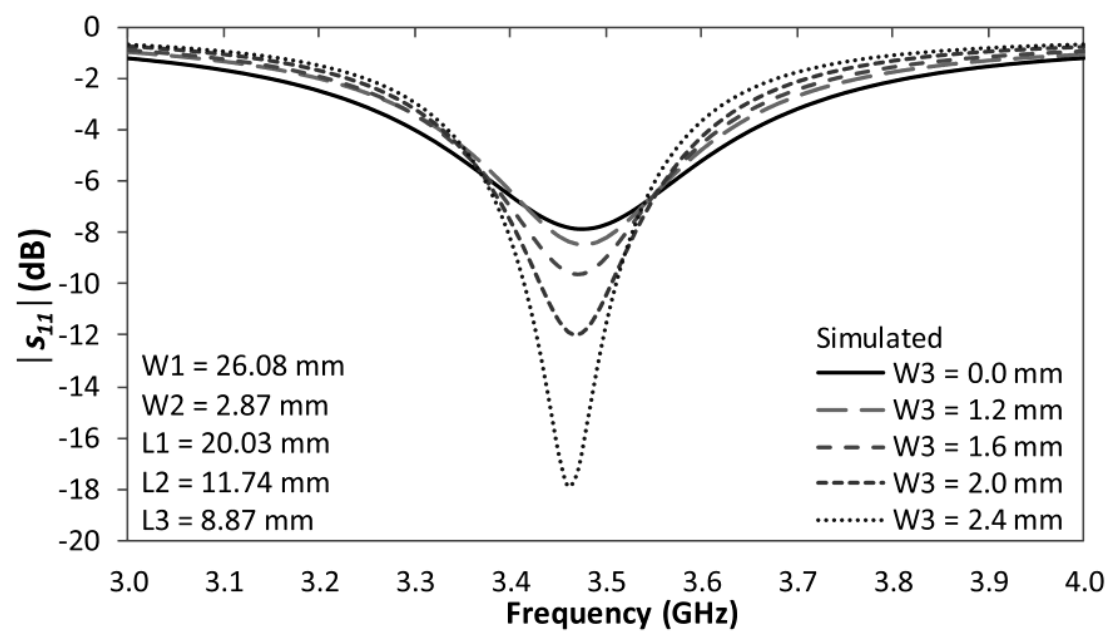

Fig. 6. Reflection coefficient simulation results for the proposed antenna for operation at $3.46 \mathrm{GHz}$ with $L_{3}=8.87 \mathrm{~mm}$ and different values of $W_{3}$. 
TABLE II. RESONANT FREQUENCY AND REFLECTION COEFFICIENT SIMULATION RESULTS FOR THE PROPOSED ANTENNA GEOMETRY

\begin{tabular}{ccc}
\hline $\boldsymbol{W}_{\mathbf{3}}(\mathbf{m m})$ & $\mathbf{F}(\mathbf{G H z})$ & $\left.\left|\boldsymbol{s}_{\mathbf{1}}\right| \mathbf{( d B}\right)$ \\
\hline Antenna geometry designed for operation at $\mathbf{1 . 7 8} \mathbf{~ G H z}$ & & \\
\hline 0 & 1.78 & -10.56 \\
1.2 & 1.78 & -12.39 \\
1.6 & 1.78 & -14.75 \\
2 & 1.78 & -20.35 \\
2.4 & 1.78 & -27.41 \\
\hline Antenna geometry designed for operation at $\mathbf{2 . 4 2} \mathbf{~ G H z}$ & & \\
\hline 0 & 2.42 & -8.81 \\
1.2 & 2.42 & -10.09 \\
1.6 & 2.42 & -11.86 \\
2 & 2.42 & -15.21 \\
2.4 & 2.42 & -28.09 \\
\hline Antenna geometry designed for operation at $\mathbf{3 . 4 6} \mathbf{~ G H z}$ & & \\
\hline 0 & 3.46 & -7.84 \\
1.2 & 3.46 & -8.35 \\
1.6 & 3.46 & -9.54 \\
2 & 3.46 & -11.87 \\
2.4 & 3.46 & -17.91 \\
\hline
\end{tabular}

It is observed that the insertion of a narrow slot along the conducting strip of a feeding microstrip line, as shown in Figs. 4, 5, and 6, enables a considerable reduction of the magnitude of the patch antenna input reflection coefficient with respect to the one of the patch antenna geometry with a traditional microstrip line.

Results for the proposed antenna geometry, fed by an axially slotted microstrip line, were obtained for $W_{3}$ values varying from 0 to $2.4 \mathrm{~mm}$, as shown in Table II. A reduction of approximately $20 \mathrm{~dB}$ was obtained for $W_{3}=2.4 \mathrm{~mm}$, as shown in Fig. 5, confirming that the proposed technique has a great potential as a tool for optimizing the impedance matching between the microstrip line and the patch antenna.

To validate the simulation results, four prototypes were fabricated and measured for the antenna resonating at $1.78 \mathrm{GHz}$, fed by a slotted microstrip line with dimensions $W_{3}=0,1.2,1.6$, and 2.0 $(\mathrm{mm})$, shown in Figs. 7(a), 7(b), 7(c), and 7(d), respectively. All the other structural parameters are the same used in previous simulations and given in Fig. 4.

Measurements were performed at the GTEMA/IFPB Microwaves Laboratory, using a network analyzer (Agilent N5230A).

The WCIP Method was applied to the antenna geometry designed for operation at $1.78 \mathrm{GHz}$, and the results were compared to Ansoft Designer software and measurements results, as shown in Figs. 8 to 11 and summarized in Table III. 


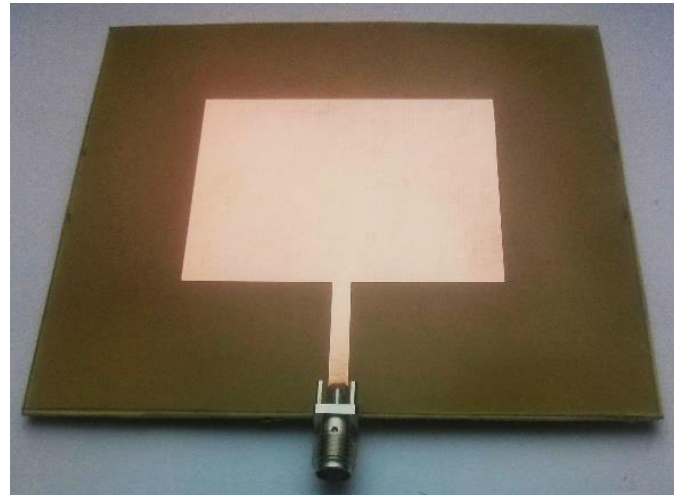

(a)

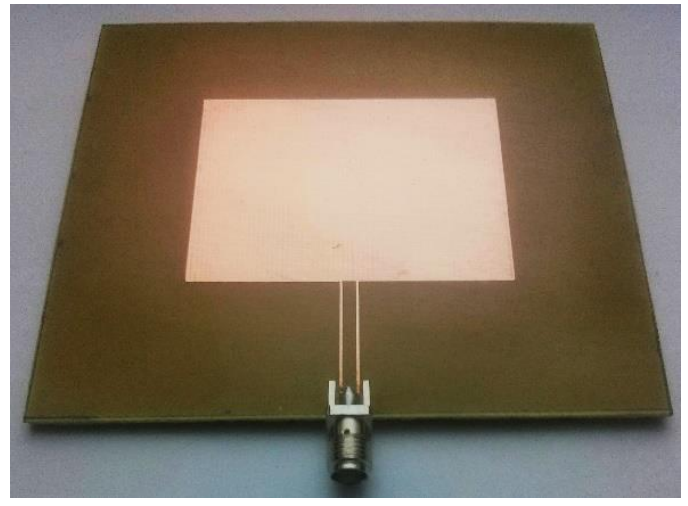

(c)

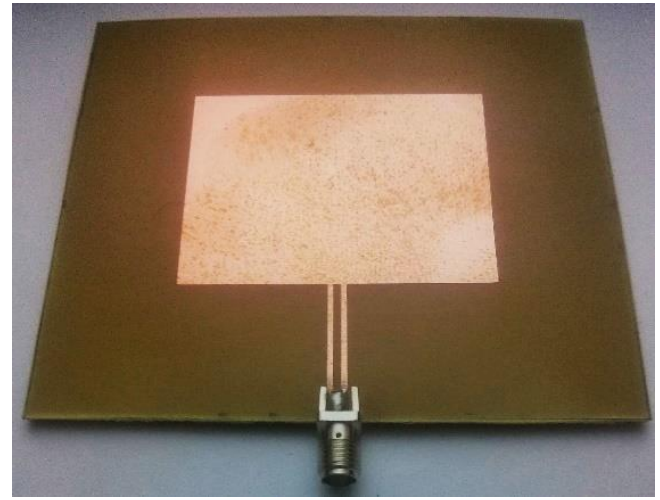

(b)

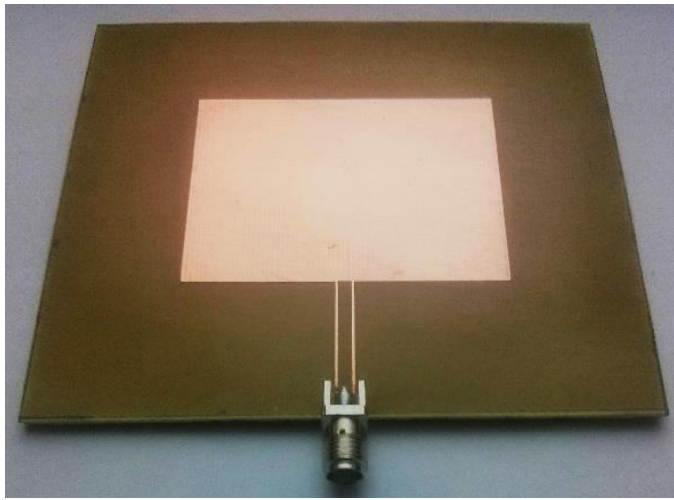

(d)

Fig. 7. Microstrip antenna prototypes on FR-4 substrates with resonant frequency at $1.78 \mathrm{GHz}$. Slot dimensions are (a) $W_{3}=$ $L_{3}=0 \mathrm{~mm}$ (without slot), (b) $W_{3}=1.2 \mathrm{~mm}$ and $L_{3}=19.96 \mathrm{~mm}$, (c) $W_{3}=1.6 \mathrm{~mm}$ and $L_{3}=19.96 \mathrm{~mm}$, and (d) $W_{3}=2.0 \mathrm{~mm}$ and $L_{3}=19.96 \mathrm{~mm}$.

Fig. 8 shows Ansoft Designer and WCIP simulations and measurements results for the reflection coefficient of the antenna prototype, shown in Fig. 7(a), without narrow slot $\left(W_{3}=0 \mathrm{~mm}\right.$ and $L_{3}=$ $19.96 \mathrm{~mm}$ ). Simulated and measured resonant frequency values are $1.78 \mathrm{GHz}$ and $1.77 \mathrm{GHz}$, respectively, exhibiting a very good agreement with a percent error of $0.56 \%$ for Ansoft Designer simulation.

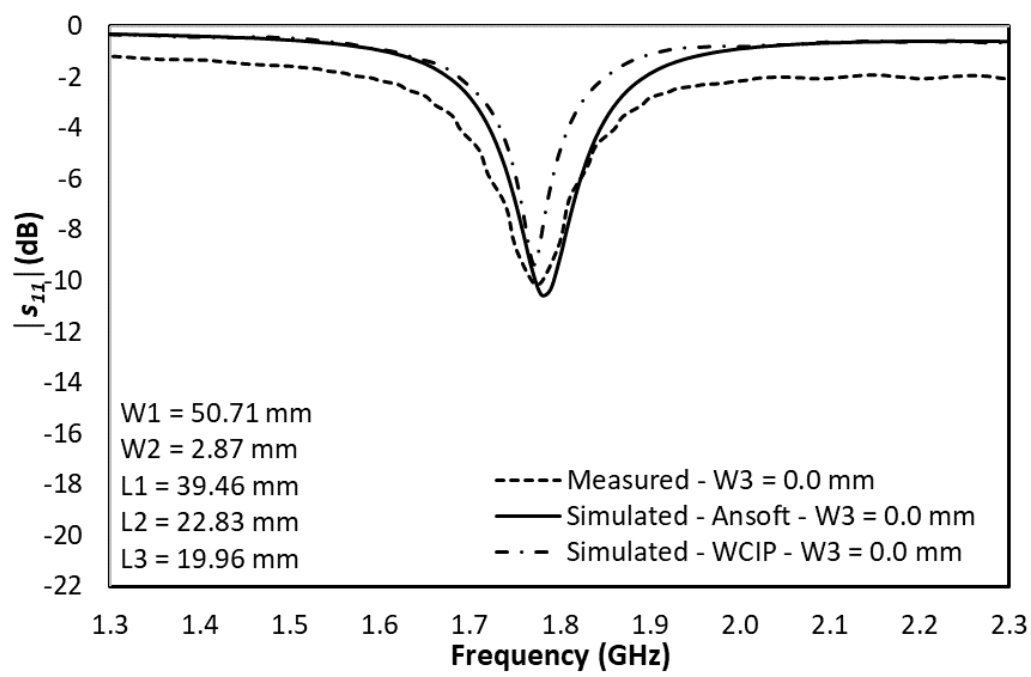

Fig. 8. Simulated and measured results for the reflection coefficient of the antenna in Fig. 7(a) without slot $\left(W_{3}=0 \mathrm{~mm}\right)$. 
Fig. 9 shows Ansoft Designer and WCIP simulations and measurements results for the reflection coefficient of the antenna prototype shown in Fig. 7(b) with narrow slot $\left(L_{3}=19.96 \mathrm{~mm}\right.$ and $W_{3}=1.2$ $\mathrm{mm}$ ). Simulated and measured resonant frequency values are $1.78 \mathrm{GHz}$ and $1.77 \mathrm{GHz}$, respectively, exhibiting a very good agreement with a percent error of $0.56 \%$ for Ansoft simulation.

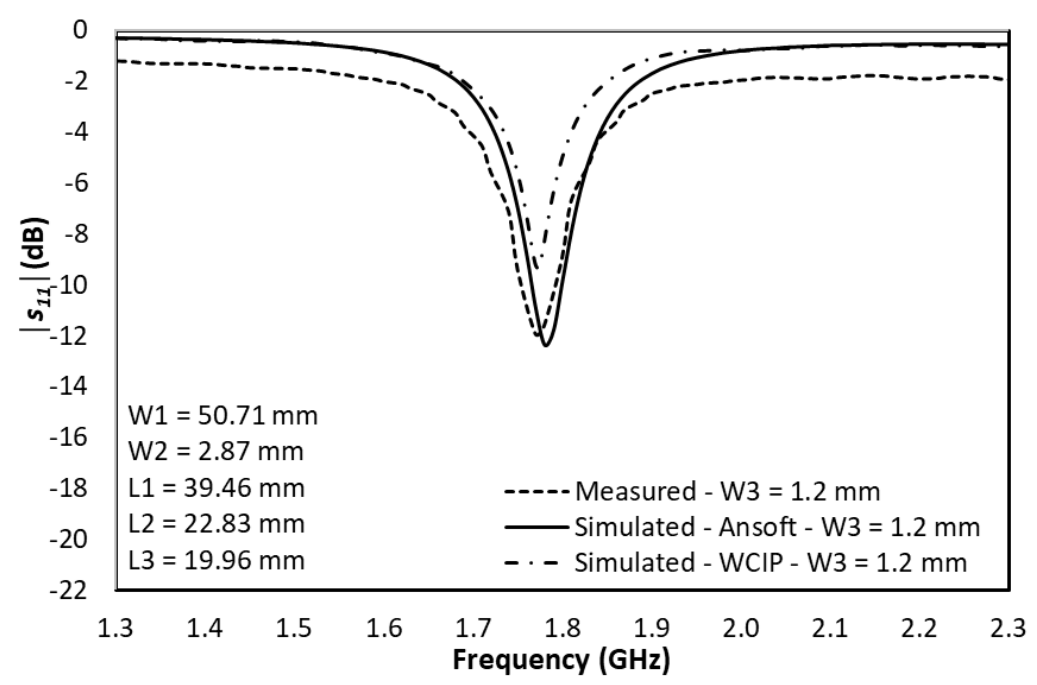

Fig. 9. Simulated and measured results for the reflection coefficient of the antenna in Fig. 7(b) with slot $\left(W_{3}=1.2 \mathrm{~mm}\right)$.

Fig. 10 shows Ansoft Designer and WCIP simulations and measurements results for the reflection coefficient of the antenna prototype shown in Figure 7(c) with narrow slot $\left(W_{3}=1.6 \mathrm{~mm}\right.$ and $L_{3}=$ $19.96 \mathrm{~mm}$ ). Simulated and measured resonant frequency values are equal to $1.78 \mathrm{GHz}$, respectively, exhibiting an excellent agreement.

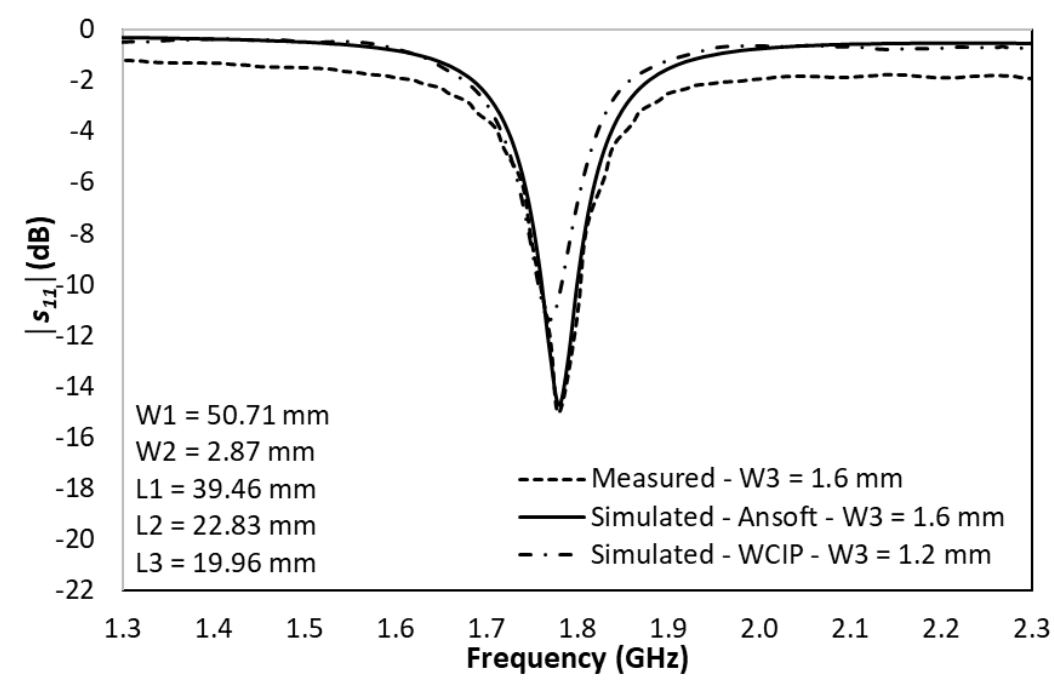

Fig. 10. Simulated and measured results for the reflection coefficient of the antenna in Fig. 7 (c) with slot $\left(W_{3}=1.6 \mathrm{~mm}\right)$.

Fig. 11 shows Ansoft Designer and WCIP simulations and measurements results for the reflection coefficient of the antenna prototype shown in Figure 7(d) with $\left(W_{3}=2.0 \mathrm{~mm}\right.$ and $\left.L_{3}=19.96 \mathrm{~mm}\right)$. Simulated and measured resonant frequency values are equal to $1.78 \mathrm{GHz}$, respectively, exhibiting a very good agreement with a percent error of $0.56 \%$ for Ansoft simulation. 


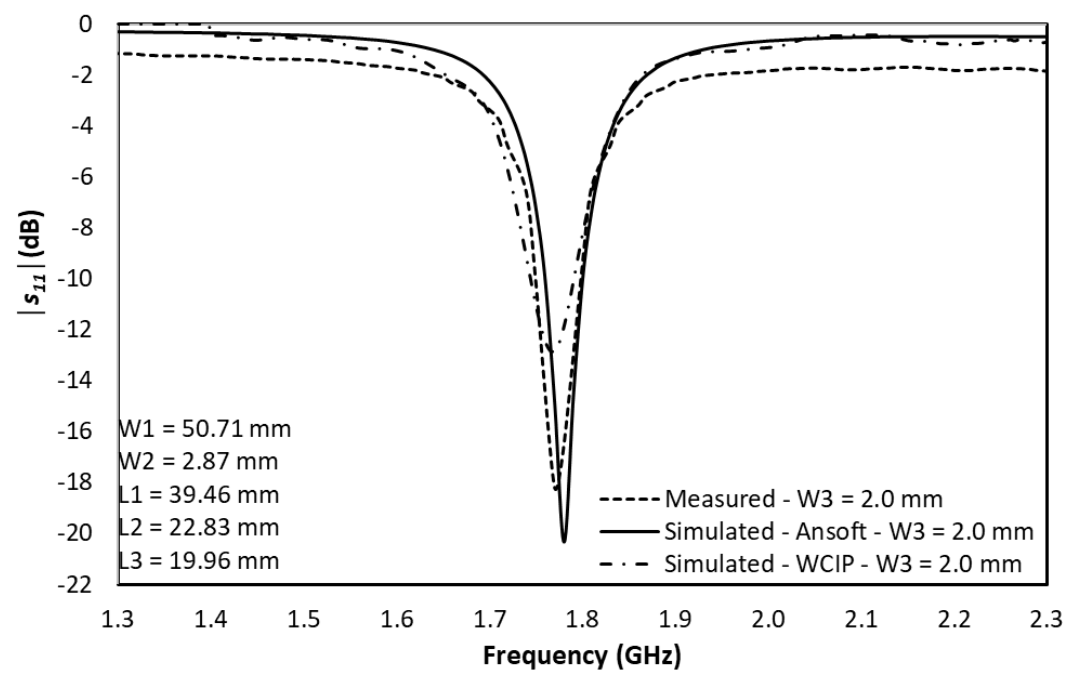

Fig. 11. Simulated and measured results for the reflection coefficient of the antenna in Fig. 7(d) with slot $\left(W_{3}=2 \mathrm{~mm}\right)$.

In all cases, an excellent agreement is observed between simulated and measured results for the resonant frequency. Simulated and measured results for the frequency behavior of the input reflection coefficient, $\left|S_{11}\right|(\mathrm{dB})$, are summarized in Table III.

In addition, the measurement results shown in Fig. 12 exhibit the efficiency of the antenna impedance matching provided by the proposed axially slotted microstrip line.

Table III. Resonant frequency and reflection coefficient simulation and measurements results for the proposed antenna geometries designed for operation at $1.78 \mathrm{GHz}$.

\begin{tabular}{|c|c|c|c|c|}
\hline & $W_{3}(0 \mathrm{~mm})$ & $W_{3}(1.2 \mathrm{~mm})$ & $W_{3}(1.6 \mathrm{~mm})$ & $W_{3}(2 \mathrm{~mm})$ \\
\hline \multicolumn{5}{|l|}{$F(G H z)$} \\
\hline Simulated - Ansoft Designer & 1.78 & 1.78 & 1.78 & 1.78 \\
\hline Measured & 1.77 & 1.77 & 1.78 & 1.77 \\
\hline Percent error $(\%)$ & 0.56 & 0.56 & 0.0 & 0.56 \\
\hline \multicolumn{5}{|l|}{$F(G H z)$} \\
\hline Simulated - WCIP & 1.77 & 1.77 & 1.77 & 1.76 \\
\hline Measured & 1.77 & 1.77 & 1.78 & 1.77 \\
\hline Percent error $(\%)$ & 0.0 & 0.0 & 0.0 & 0.56 \\
\hline \multicolumn{5}{|l|}{$\left|s_{11}\right|(d B)$} \\
\hline Simulated - Ansoft Designer & -10.56 & -12.39 & -14.75 & -20.35 \\
\hline Measured & -10.08 & -11.94 & -15.04 & -18.12 \\
\hline \multicolumn{5}{|l|}{$\left|s_{11}\right|(d B)$} \\
\hline Simulated - WCIP & -9.35 & -10.22 & -11.39 & -12.84 \\
\hline Measured & -10.08 & -11.94 & -15.04 & -18.12 \\
\hline
\end{tabular}




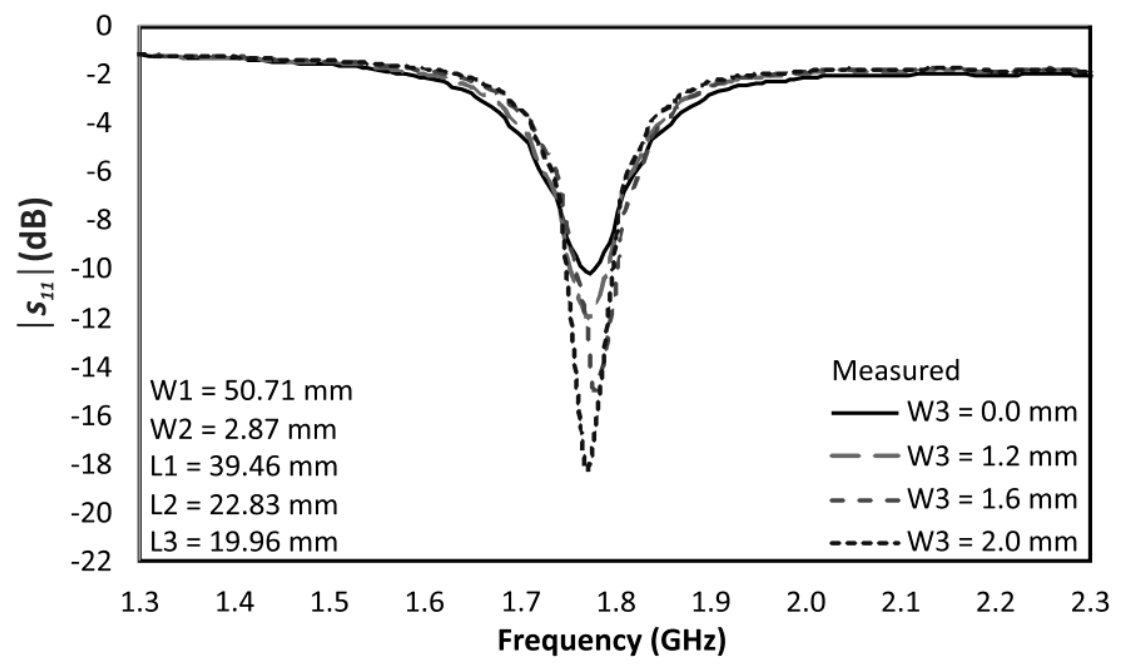

Fig. 12. Measured results for the reflection coefficient of the antennas shown in Fig. 7.

Furthermore, simulation has been performed on Ansoft HFSS software for the surface current density on the manufactured antenna prototypes shown in Fig. 7. The obtained results are shown in Fig. 13 confirming the enhancement of the microstrip antenna impedance matching provided by the use of axially slotted microstrip lines.
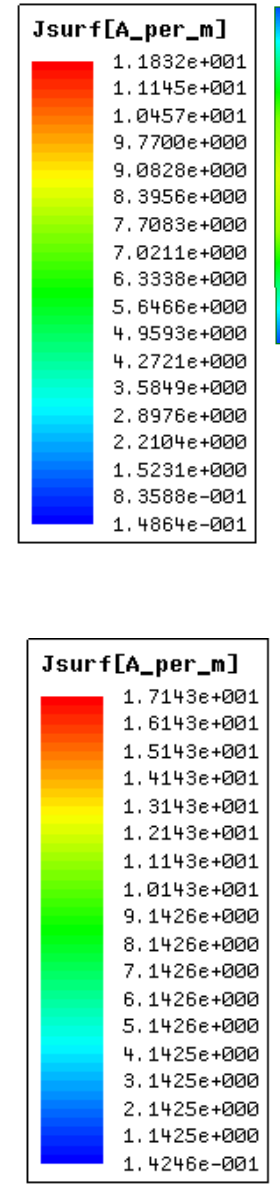

(a)

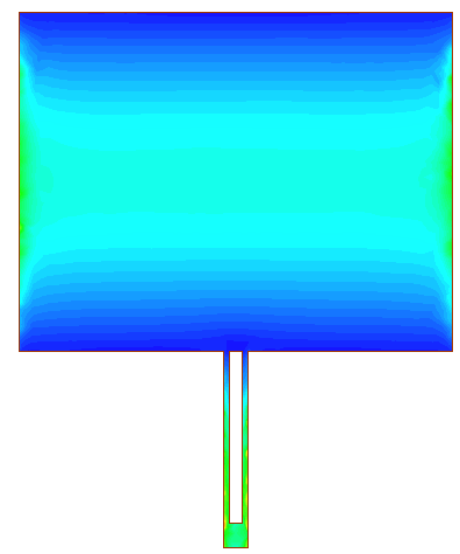

(c)
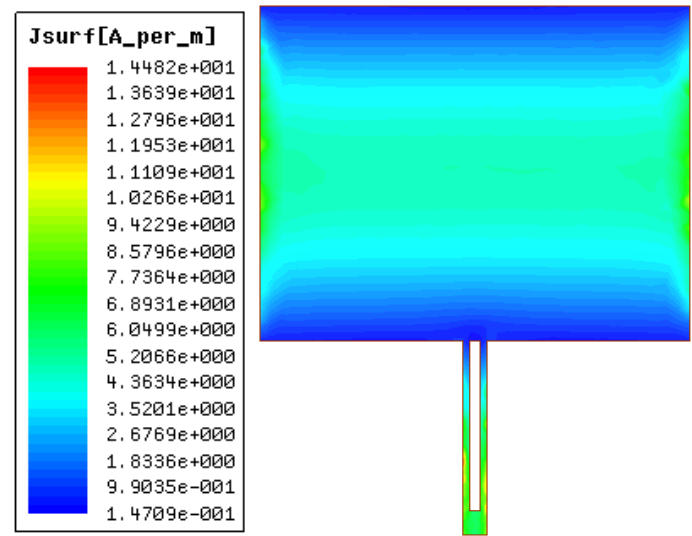

(b)
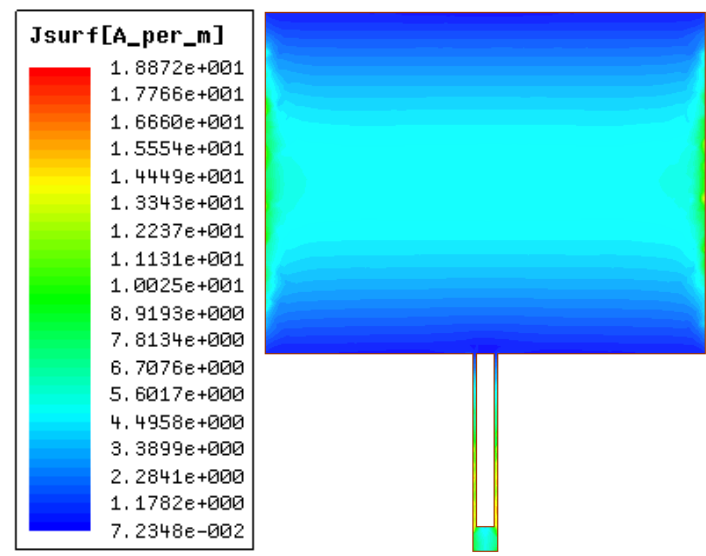

(d)

Fig. 13. Surface current density distribution simulated results for the microstrip antenna prototypes shown in Fig. 7. Slot dimensions are: (a) $W_{3}=L_{3}=0 \mathrm{~mm}$, (b) $W_{3}=1.2 \mathrm{~mm}$ and $L_{3}=19.96 \mathrm{~mm}$, (c) $W_{3}=1.6 \mathrm{~mm}$ and $L_{3}=19.96 \mathrm{~mm}$, and (d) $W_{3}=2.0$ $\mathrm{mm}$ and $L_{3}=19.96 \mathrm{~mm}$. Resonant frequency is $1.78 \mathrm{GHz}$ and dielectric substrate is FR-4. 


\section{CONCLUSION}

This paper proposed an alternative for obtaining impedance matching in patch antenna designs, using an axially slotted microstrip line. Parametric analyses were performed using Ansoft Designer software and WCIP Method. In addition, prototypes were fabricated and measured, to validate the proposed impedance matching technique. An excellent agreement is observed between simulated and measured results.

For the microstrip patch antenna with resonant frequency at $2.42 \mathrm{GHz}$, the use of the proposed impedance matching technique has enabled, for $W_{3}=2.4 \mathrm{~mm}$, a significative reduction of about $68.64 \%$ on the reflection coefficient, $\left|s_{11}\right|(\mathrm{dB})$, of the considered patch antenna, reducing from -8.81 $\mathrm{dB}$ (original geometry, without impedance matching) to $-28.09 \mathrm{~dB}$ (with axially slotted microstrip impedance matching), according to simulation results.

This work has shown that the proposed technique enabled the impedance matching of microstrip antennas, with potential applications in the development of compact antennas and filters designs, with different patch formats, including those with fractal and metamaterial inspired geometries. In addition, it can reduce abrupt line transitions, as in the case of $\lambda / 4$ transformers, changes in patch shape, as in the case of inset-feed, and increasing the overall size of the antenna, as in the case of stubs, while providing microstrip antenna impedance matching.

\section{ACKNOWLEDGMENT}

This work was supported by CNPq, under covenant 573939/2008-0 (INCT-CSF), Federal University of Rio Grande do Norte (UFRN), and Federal Institute of Education, Science and Technology of Paraíba (IFPB).

\section{REFERENCES}

[1] C. A. Balanis, Antenna Theory: Analysis and Design, John Wiley \& Sons, 2005.

[2] M. S. Alam, Y. Wang, N. Nguyen-Trong, and A. Abbosh, "Compact circular reconfigurable antenna for high directivity and $360^{\circ}$ beam scanning," IEEE Antennas Wirel. Propag., pp. 1492-1496, 2018.

[3] E. J. B. Rodrigues, A. G. D'Assunção, and H. W. C. Lins, "Fast and accurate synthesis of electronically reconfigurable annular ring monopole antennas using particle swarm optimisation and artificial bee colony algorithms", IET Microw. Antennas Propag., vol. 10, pp. 362-369, 2016.

[4] E. E. C. Oliveira, P. H. D. F. Silva, A. L. P. S. Campos, and A. G. D'Assunção, "Small-size quasi-fractal patch antenna using the Minkowski curve", Microw. Opt. Technol. Lett., pp. 805-809, 2010.

[5] D. R. Minervino, A. G. D'Assunção, and C. Peixeiro, "Mandelbrot fractal microstrip antennas," Microw. Opt. Technol. Lett., vol. 58, pp. 83-86, 2016.

[6] N. N. Yoon, N. Ha-Van, and C. Seo, "High-gain and wideband aperture coupled feed patch antenna using four split ring resonators", Microw. Optical Technol. Lett., pp. 1997-2001, 2018.

[7] D. B. Brito, X. Begaud, A. G. D’Assunção, and H. C. C. Fernandes, "Ultra wideband monopole antenna with split ring resonator for notching frequencies", Proc. 4th Europ. Conf. Antennas Propagation (EuCAP 2010), Barcelona, Spain, vol. 1. pp. 1-5, 2010. 
DOI: http://dx.doi.org/10.1590/2179-10742019v18i21556

[8] D. B. Brito, A. G. D’Assunção, R. H. C. Maniçoba, and X. Begaud, "Metamaterial inspired Fabry-Pérot antenna with cascaded frequency selective surfaces," Microw. Opt. Technol. Lett., vol. 55, pp. 981-985, 2013.

[9] N.-W. Liu, L. Zhu, W.-W. Choi, and J.-D. Zhang, "A Low-profile differentially fed microstrip patch antenna with broad impedance bandwidth under triple-mode resonance”, IEEE Antennas Wirel. Propag. Lett., pp. 1478-1482, 2018.

[10] S. Mulla and S. S. Deshpande, "Compact multiband antenna fed with wideband coupled line impedance transformer for improvement of impedance matching", Microw. Opt. Technol. Lett., no. 59, pp. 2341-2348, 2017.

[11] M. Mustaqim, B. A. Khawaja, A. A. Razzaqi, S. S. H. Zaidi, S. A. Jawed, and S. H. Qazi, "Wideband and high gain antenna arrays for UAV-to-UAV and UAV-to-ground communication in flying ad-hoc networks", Microw. Opt. Technol. Lett., pp. 1164-1170, 2018.

[12] A. T. Abed and M. S. J. Singh, "Slot antenna single layer fed by step impedance strip line for Wi-Fi and Wi-Max applications”, Electron. Lett., vol. 52, pp. 1196-1198, 2016.

[13] A. Gorai, M. Pal and R. Ghatak, “A Compact fractal-shaped antenna for ultrawideband and bluetooth wireless systems with WLAN rejection functionality”, IEEE Antennas Wirel. Propag. Lett., vol. 16, pp. 2163-2166, 2017.

[14] H. Aliakbari, A. Mallahzadeh, and S. M. A. Nezhad, "A tri-band, small size radio frequency identification tag antenna with U-shaped slots”, Microw. Opt. Technol. Lett., no. 54, pp. 1975-1978, 2012.

[15] C. Mbinack, E. Tonye, and D. Bajon, "Microstrip-line theory and experimental study for the characterization of the inset-fed rectangular microstrip-patch antenna impedance”, Microw. Opt. Technol. Lett., no. 57, pp. 514-518, 2015.

[16] H. L. Peng, Z. Tang, Y. P. Zhang and J. F. Mao, "Cavity model analysis of a dual-probe-feed circular microstrip patch antenna”, IEEE Antennas Wirel. Propag. Lett., vol. 15, pp. 44-47, 2016.

[17] M. Titaouine, A. G. Neto, H. Baudrand, and F. Djahli, "WCIP method applied to active frequency selective surfaces," J. Microw. Optoelectron. Eletromagn. Appl., vol. 6, pp. 1-16, 2007.

[18] M. Titauoine, N. Raveu, A. G. Neto, and H. Baudrand, "The WCIP method: theory and applications," Advances in Engineering Research, vol. 6, pp. 143-176, 2013.

[19] H. Baudrand, M. Titaouine, and N. Raveu, "The Wave Concept in Electromagnetism and Circuits: Theory and Applications", Wiley, 2016.

[20] A. G. D'Assunção Jr., Analysis of integrated circuits and FSS using WCIP for applications at microwaves and terahertz bands (in Portuguese), Ph.D. Dissertation, Federal University of Campina Grande, PB, Brazil, 2012.

[21] V. P. S. Neto, A. G. D'Assunção, and H. Baudrand, "Analysis of finite size nonuniform stable and multiband FSS using a generalization of the WCIP method”, IEEE Trans. Electromagn. Compat., vol. 60, no. 6, pp. 1802-1810, Dec. 2018.

[22] A. G. D'Assunção Jr., G. Fontgalland, A. Gomes Neto, and Henri Baudrand, "Frequency selective surface filters with polarized band pass/band reject performances," Microw. Opt. Technol. Lett., no. 56, pp. 483-487, 2014.

[23] "Microstrip Patch Antenna Calculator", EM: Talk - Electromagnetics \& Microwave Engineering, 2006. [Online]. Available: http://www.emtalk.com/mpacalc.php. [Accessed 30 September 2018]. 